University of Nebraska - Lincoln

DigitalCommons@University of Nebraska - Lincoln

To Improve the Academy

Professional and Organizational Development

Network in Higher Education

1997

\title{
Incorporating Theories of Teacher Growth and Adult Education in a Faculty Development Program
}

Alenoush Saroyan

Cheryl Amundsen

Cao Li

Follow this and additional works at: https://digitalcommons.unl.edu/podimproveacad

Part of the Higher Education Administration Commons

Saroyan, Alenoush; Amundsen, Cheryl; and Li, Cao, "Incorporating Theories of Teacher Growth and Adult Education in a Faculty Development Program" (1997). To Improve the Academy. 387.

https://digitalcommons.unl.edu/podimproveacad/387

This Article is brought to you for free and open access by the Professional and Organizational Development Network in Higher Education at DigitalCommons@University of Nebraska - Lincoln. It has been accepted for inclusion in To Improve the Academy by an authorized administrator of DigitalCommons@University of Nebraska - Lincoln. 
Saroyan, A., Amumdsen, C., \& Li, C. (1997). Incorporating theories of teacher growth and acult education in a faculty development program In D. DeZure (Ed), To Improve the Academy, Vol. 16 (pp. 93-110). Stillwater, OK: New Forums Press and the Professional and Organizational Development Network in Higher Education. Key Words: Faculty Development Programs, Instructional Development, Adult Students.

\section{Incorporating Theories of Teacher Growth and Adult Education in a Faculty Development Program}

\section{Alenoush Saroyan}

Cheryl Amundsen

Cao Li

McGill University

This paper describes a theory-based faculty development program and provides preliminary evidence as to its effectiveness in promoting change in thinking about teaching. The program design was based on Ramsden's (1992) theory of teacher growth and Mezirow's (1991) transformative theory in adult education. The program was offered as a three-credit course to graduate students and as a week-long (40 hours) workshop to faculty. Assessment included responses to pre-post-questions about participants' views from teaching. Results indicate that both groups changed their focus from viewing teaching as transmitting knowledge to a more integrated and complex conception of teaching. 
Increasingly, teaching at the postsecondary level is being characterized as a complex activity rather than as a set of specific skills (Leinhardt \& Greeno, 1986). That is, teaching is being defined not only by overt actions but also by beliefs, views, and assumptions held about teaching (Calderhead, 1991; Elbaz, 1991; Kagan \& Tippins, 1993; Ramsden, 1992). Within this perspective, attaining a level of teaching competency, as a minimum, calls for an integrated view of the subject to be taught, the role of the learner and the teacher, and ultimately, the desired learning. For faculty developers who subscribe to this view, the challenge is how to conceptualize and implement interventions that support and encourage the development of a coherent and integrated view of teaching and learning and the skillful delivery of instruction. Our purpose in this paper is to demonstrate the way in which faculty development interventions can promote such a complex view and to provide some preliminary evidence as to the effectiveness of such a program offered in two formats.

\section{Relevant Literature}

Two existing bodies of literature are particularly useful in informing the design of faculty development programs that aim at changing individuals' thoughts as well as actions. The first pertains to the literature on teaching growth at the postsecondary level which highlights the importance of structured reflection, the support and critique of peers (Sherman, Barksdale \& Reif, 1987), a better understanding of the subject matter (Shulman, 1987), and a willingness to take risks in teaching (Van Note Chism \& Sanders, 1986). This literature also suggests that teachers' beliefs about students, learning, classrooms, and the subject matter may be a hindrance in one's development (Pajares, 1992). That is, for example, teachers may view their students from the memories of themselves as learners which may block further understanding of students' needs and motivations (Grossman, 1991; Kagan, 1991). Of the several frameworks which seek to characterize the development of teacher thinking and practice in higher education, in our opinion, the most comprehensive is the one proposed by Ramsden (1992). 


\section{Ramsden's Theories of Teaching}

Ramsden's conceptualization of teaching is based on his extensive research on student learning in higher education (Ramsden 1983, 1988a, 1988b; Ramsden \& Entwistle, 1981) and a series of unpublished case studies of instructors. He argues that teaching and learning must be thought of inseparably. He states that the answer to improving student learning "lies in the connection between students' learning of a particular content and the quality of our teaching of that content... Good teaching and good learning are linked through the students' experiences of what we do. It follows that we cannot teach better unless we are able to see what we are doing from their point of view" (Ramsden, 1992, p. 86).

Ramsden describes three progressively sophisticated "theories" and associates each with specific views of teaching and learning. In the first theory, the view of teaching and learning is fragmented. The role of the professor and the student, the teaching and learning processes, the content and context, while important, are mostly unrelated. Instructors at this level tend to think that subject matter must be transmitted to students and that teaching and learning are part of a simple input-output process. The instructor's focus is on himself or herself as the one who transmits knowledge and expertise, and not on learning, the rightful outcome of the process. The primary tenet of the second theory is organizing student activity. The instructor recognizes that engaging students more actively increases learner motivation; there is more concern for what the students are doing and what the professor's interaction with them should be. Typically, at this level, instructors try one or more new methods, emphasizing the belief that improved teaching involves enlarging one's repertoire of teaching methods. The focus on engaging students in activities stops short of making intentional connections between the desired learning and the selected activity or teaching method. In the third and most evolved theory, all aspects of the teaching and learning process are well integrated. Teaching, at this level, means cooperatively working with learners to achieve understanding.

Ramsden (1992) further strengthens his conceptualization by placing the three theories of teaching within a broader model which 
includes the context in which teaching takes place and the value of feedback. In this model, context acts as a filter between thinking and teaching and is described as an instructor's perception of variables, such as disciplinary norms, organizational patterns, and institutional variables.

Following the same argument, Ramsden (1992) contends that any activity aimed at improving teaching needs to engage instructors in ways that are appropriate to the development of their understanding of teaching. Of major importance in making learning about teaching meaningful to instructors is to place the experience in the context of their specific subject area and then to encourage them to deliberate about what they do and why they do it. For this reason, Ramsden would argue that skills-based faculty development activities, such as training in lecturing and discussion techniques, without contextualizing them within the instructor's current understanding of teaching and within their subject matter are bound to fail in improving teaching competency.

\section{Mezirow's Theory of Transformative Learning}

Adult education, in particular the theory of transformative learning (Mezirow, 1991), is the second body of literature that is useful in the design of faculty development programs that aim at changing individuals' thoughts and actions. This theory purports that, for most adult learners, change in practice occurs when there is a change in the basic assumptions held about themselves as learners, the role of the teacher, and the goal of education. Such a change is mediated by examining assumptions candidly and by identifying "distorted"views held on teaching and learning. What is the assumption? How did we come to hold this assumption? Why does this assumption matter? These questions can lead one to reflect on the source of the problem (Cranton, 1994, p. 731). It has been argued that reflection may be the bridge that connects the gap between thinking and practice (Calderhead, 1991) and perhaps even the key process in changing practice (Schön, 1983). However, caution is advised in that 'the relationship between teachers' thoughts and knowledge and their practice is neither straightforward nor well understood" (Calderhead, 1991, p. 532). In 
short, transformative learning theory can cast faculty development programs as a process by which faculty become aware of their assumptions about teaching and revise these assumptions based on critical self-reflection and peer critique (Cranton, 1994).

\section{Underlying Assumptions of the Faculty Development Program}

In this paper, we describe a faculty development program which we have developed based on the above-described theories. We distinguish this program from other faculty development activities along three dimensions: goals, content, and intensity of the program. Whereas faculty development programs generally tend to focus on the teaching of specific skills and techniques in a prescriptive format (Levinson-Rose \& Menges, 1981; Weimer \& Lenze, 1991), we have intentionally focused on the process underlying teacher thought and action. We believe that change in teaching practice is an introspective and lengthy process which is mediated by questioning personal assumptions and learning from risks taken in instructional contexts. Furthermore, we contend that this process is facilitated by peer and institutional support and that there should be an appreciation that it takes considerable time before newly developed thoughts can be turned into action (Kozma, 1985). In initiating the process of change, we believe collaborative dialogue plays an important role because it affords a common language by means of which experiences can be articulated and interpreted (Clark, 1991; Pugach \& Johnson, 1990; Qualters, 1995). In the context of the development of teaching, professional dialogue leads to "integrating large bodies of practice into sensible perspectives on the business of teaching" (Little, 1982, p. 331).

Our program, which is explained in greater detail in the following section, has two components: course design and micro-teaching. In the course design component, we provide a context within which individuals examine their assumptions about their subject matter and the most appropriate ways to teach it, the learning they expect their students to achieve as a result of their teaching, and the learners with whom they work. In the micro-teaching component, the conceptual 
decisions made in the course design component are put into practice. Thus, these two components are purposefully designed to make the integration of intellectual and practical problem-solving in teaching possible.

The effectiveness of skills-based faculty development activities is typically established by means of satisfaction ratings by participants, evidence of increased declarative and/or procedural knowledge, participant ratings of the instructor, and evidence of increased student learning (Levinson-Rose \& Menges, 1981; Weimer \& Lenze, 1991). Not surprisingly, satisfaction ratings are the easiest and hence most frequently used method. Given that the focus of the program described here is somewhat different from typical faculty development programs, we use a different method of evaluation. That is, we examine the degree of change in participants' conceptions of teaching and learning. Even though this is not a traditional way of assessing effectiveness, it is perhaps a more appropriate way when the objective of the study is examining the process of change in thinking. As an additional measure, we also conduct a satisfaction-based evaluation.

\section{Description of the Program}

The multidisciplinary course design and teaching development program are implemented in two different formats. One is as a three credit course for graduate students and the other is a 40-hour weeklong workshop for professors. While the general purpose of this program is product-oriented, that is, it aims at enabling participants to design a course and demonstrate skill and self-confidence in teaching it, it also promotes a particular philosophy about teaching. The underlying principles of this philosophy are (1) that teaching is a complex, cognitive activity and doing it well extends far beyond mastering a set of skills and (2) in addition to content knowledge, teaching at the postsecondary level requires knowledge of course design principles and a highly developed set of metacognitive skills that enable individuals to reflect continuously on and adjust their teaching practice.

The approach used in this program engages participants intellectually and draws on their particular disciplinary knowledge to inform the design and the teaching of their selected course. The course design 
component generally follows the traditional instructional design sequence (see for example Dick \& Carey, 1985; Kemp, Morrison, \& Ross, 1994 ). At the outset, participants engage in an analysis of the structure of knowledge comprising their courses and the identification of major concepts and their relationship to one another through concept mapping. Each person prepares his/her course according to a personal conceptual representation rather than by a set of previously delineated topics, as in, for example, a textbook. After this conceptual exercise, expected learning outcomes are identified and teaching strategies that are more likely to promote the desired learning are selected. Finally, appropriate ways of evaluating both learning and teaching that are consistent with the desired student learning are specified. Throughout, the emphasis is on the dynamic rather than the linear characteristic of course design. The importance of maintaining congruence among selected content, learning outcomes, teaching strategies, and evaluation is also highlighted.

In the micro-teaching component, participants select content from the course they are designing to teach to their peers. Putting theory into practice, individuals select those strategies which are most likely to foster the learning they have specified (for their peers) at the beginning of their session. Self and peer-critique are solicited directly after the session. Participants are also asked to complete a written self-critique while viewing the video at home. After the first microteaching session, participants are requested to experiment with an alternative strategy in order to gain a broader experience of teaching methods.

One of the strengths of this format is that each individual considers various elements of course design and teaching in the context of his/her own discipline. Another is that participants are forced to assume both the role of instructor and student. In doing so, they develop an appreciation for some of the teaching and learning issues in various disciplines. More importantly, however, they get a feeling for how actual students might react to an instructional situation such as the one they have experienced.

The program was first offered by the Centre for University Teaching and Learning at McGill University as a three-credit graduate course in 1989 and has been offered every fall and winter term since 
then. Typically, graduate students who intend to pursue academic careers enroll in this course. Every attempt is made to maintain a multi-disciplinary mix and registration is intentionally limited to 16 to accommodate micro-teaching activities.

During the initial four years (eight terms), the course was taught by both or one of the first two authors. The high ratings of the course for this period (average of course ratings $=4.8$ on a scale of 1-5 in which 5 is the highest rating) prompted discussion among Centre members about ways in which faculty could be engaged in a similar process. At about the same time, one of the authors had the opportunity to speak with Peter Frederick, one of the staff who offers the annual Great Lakes College Association course design workshop, and to exchange ideas about intensive workshops for graduate students. The outcome of these discussions was a decision to offer an intensive, week-long ( $40 \mathrm{hrs}$.) workshop using the same approach as used in the course for faculty. We acknowledged that this format would not accommodate an equally extended period of structured reflection on teaching. Nonetheless, in our view, the shortened format was the only way to secure commitment from a relatively large group of faculty members to attend the entire workshop.

The first workshop was offered in the spring of 1993 and has been offered every year. It is promoted as a non-remedial activity and participation is voluntary. The content of the workshop is the same as the credit course, although the format is somewhat changed. The graduate course is structured more as a standard course in which most of the work on course design takes place outside the classroom as homework assignments. In the week-long workshop for faculty, participants are assigned to one of four small groups from the onset. Except for some general instruction in the large group, participants remain in their small groups to work on their course design and to do their micro-teaching. This arrangement has necessitated the addition of two instructors in addition to the original two who had taught the credit course to the graduate students. The additional two faculty developers are also experienced members of the Centre and follow the same philosophy in their teaching practice. The first year this faculty workshop was offered, it was rated highly (mean rating of 4.71 on a scale of $1-5$ in which 5 is the highest rating) by participants. Sub- 
sequent ratings have been equally high. More impressive, however, has been the level of enthusiasm and commitment of participants who are generally attracted to this program because of their personal interest in teaching. A letter of invitation, sent from the Vice Principal Academic to the Deans, invites nominations of up to three individuals from each faculty. This process ensures a good multidisciplinary mix and a very wide range of teaching experience, from one year to thirty years. The workshop is free of charge and individuals are not remunerated for attending it. They are, however, able to refer to it when they submit a teaching portfolio for tenure and promotion.

While there are obvious differences in the graduate student and faculty groups, there are also some similarities which justify discussing them together in this paper. Student participation in the credit course is voluntary (although since 1995, it is a mandatory core course for some programs); so is participation in the workshop. In fact, for the workshop format, we purposely invite individuals who have an interest in teaching rather then those who have "teaching problems" to attend. We have found that one-to-one consultations are most effective for instructors who do not know how to put a course together or interact with students. Both programs are $\mathbf{4 0}$ hours long and both groups are multi-disciplinary.

\section{Method}

Routinely, we administer a needs assessment questionnaire to participants in our credit course (Appendix A) and teaching and course design workshop (Appendix B), which among other things, solicits participants' views on teaching. Similarly, at the end, as part of the course evaluation and as a comparative database to measure change, participants are asked to revisit the same question and to write a statement about their current view of teaching. Data reported here were collected from the 1993 winter term course for graduate students $(N=16)$ and the May 1993 workshop for faculty $(N=25)$.

The participants were asked the following question:

Please define teaching as you view it at the present time. Some ideas to prompt your thoughts might be: What is the role of the teacher/pro- 
fessor? What kinds of teaching activities might a teacher/professor engage in? What are the most important aspects of teaching?

Statements that were generated from the above question during these sessions were segmented, using a complete idea as the unit for a segment. The segments were then coded according to the three theories of teaching proposed by Ramsden (1992). As described earlier, the theories in Ramsden's framework represent "three generic ways of understanding the role of the teacher in higher education" (p. 111).

The coding was carried out by two individuals who were familiar with Ramsden's framework. Each coded the statements independently. There was $96 \%$ agreement on the coding among the two. Frequency tables were generated for each of the two formats with regard to the way in which participants talked about teaching before and after the program. Comparisons of statements generated before and after the program in each of the two instructional formats was carried out by chi square analysis.

\section{Results}

Figures 1 and 2 show the frequency of segments coded as Theories 1,2 and 3 before and after the instructional programs for students and for faculty, respectively.

As can be seen in Figure 1, for the graduate students, $14.29 \%$ of the segments were coded as Theory 1 (teaching as telling), but the majority of segments (45.45\%) were coded as Theory 3 (teaching as making learning possible) before the program began. At the end of the program, the number of statements coded as Theory 1 dropped to $5 \%$ and the number of statements coded as Theory 3 increased to $60 \%$. Chi square analysis, however, showed that this change was not significant $\left(\mathrm{x}^{2}=5.56, p=.149\right)$. Moving to Figure 2, which is based on data from the faculty workshop, it can be seen that $34.02 \%$ of the segments were coded as Theory 1 and $32.02 \%$ as Theory 3 before the program began. At the end of the program, no statements qualified as Theory 1 and there was a considerable increase in statements coded as Theory $3(83.33 \%)$. Subsequent chi square analysis showed that this difference was significant $\left(\mathrm{x}^{2}=20.53, p<.000\right)$. 
The design of this study did not justify statistical comparisons between groups because of the differences in the format and the differences among participants. However, there are four particularly interesting trends to note when both groups are considered. The first is that in both cases, change is in a desirable direction; that is there is movement from viewing teaching as transmission of information (Theory 1) to viewing teaching as an integrated process (Theory 3). The second is that, at the outset and in comparison to graduate students, faculty's statements place them at a less sophisticated level than the students (i.e., they provide more Theory 1 and fewer Theory 3 statements). At the end of the program, however, faculty express themselves in more sophisticated language as per Ramsden's (1992) theories than the students do (i.e., they provided no Theory 1 statements and considerably more Theory 3 statements than the graduate students). The third is that the change in the statements made by faculty

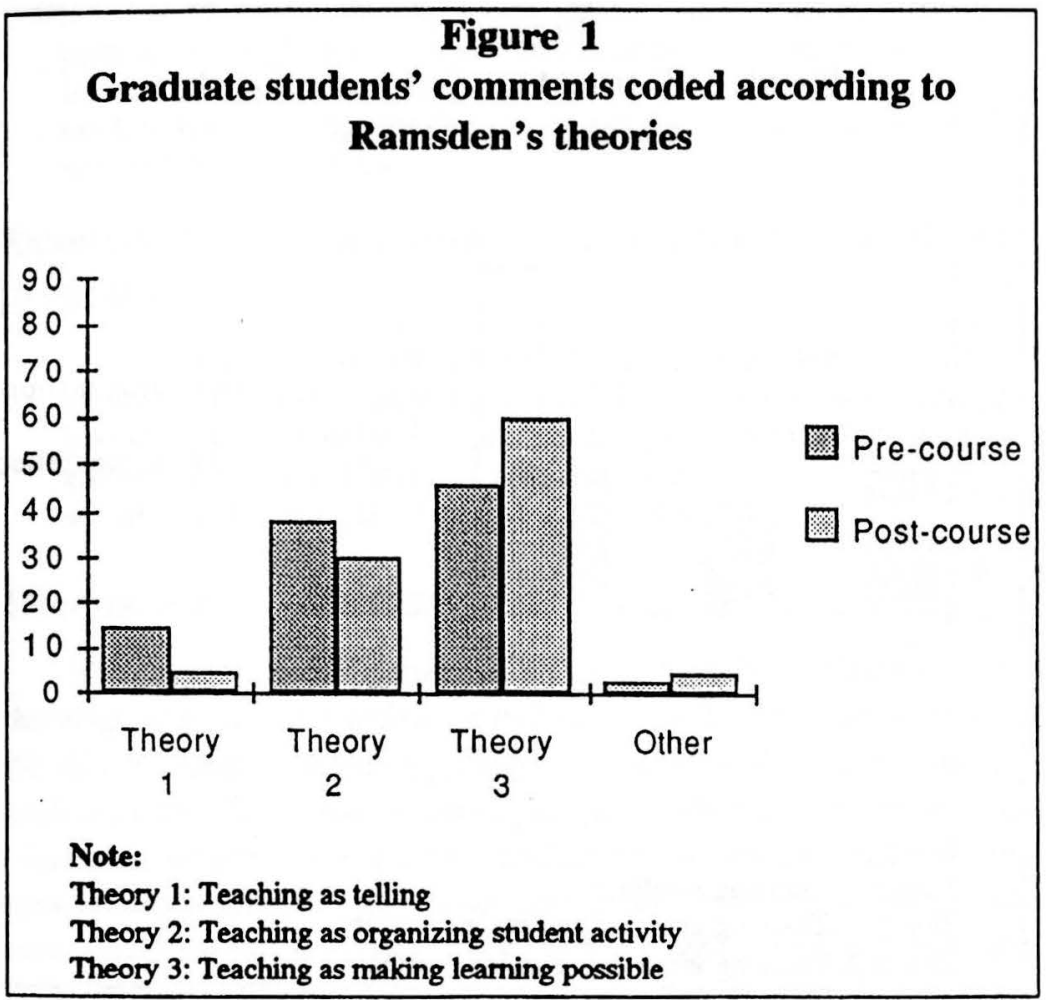


is more pronounced than the change observed in the statement made by students. Finally, in both cases change is more observable at the level of Theories 1 and 3 than at the level of Theory 2, which represents teaching as organizing student activities.

To provide a flavor for the actual ways in which graduate students and faculty expressed themselves on these topics, we provide below some verbatim excerpts from the transcripts. Again, these statements are chosen because they add a qualitative dimension to the information provided in Figures 1 and 2. They show an increased appreciation of the course design as an interrelated process rather than a linear one and a regard for the teaching process from the learner's perspective rather than from the perspective of the disseminator of information.

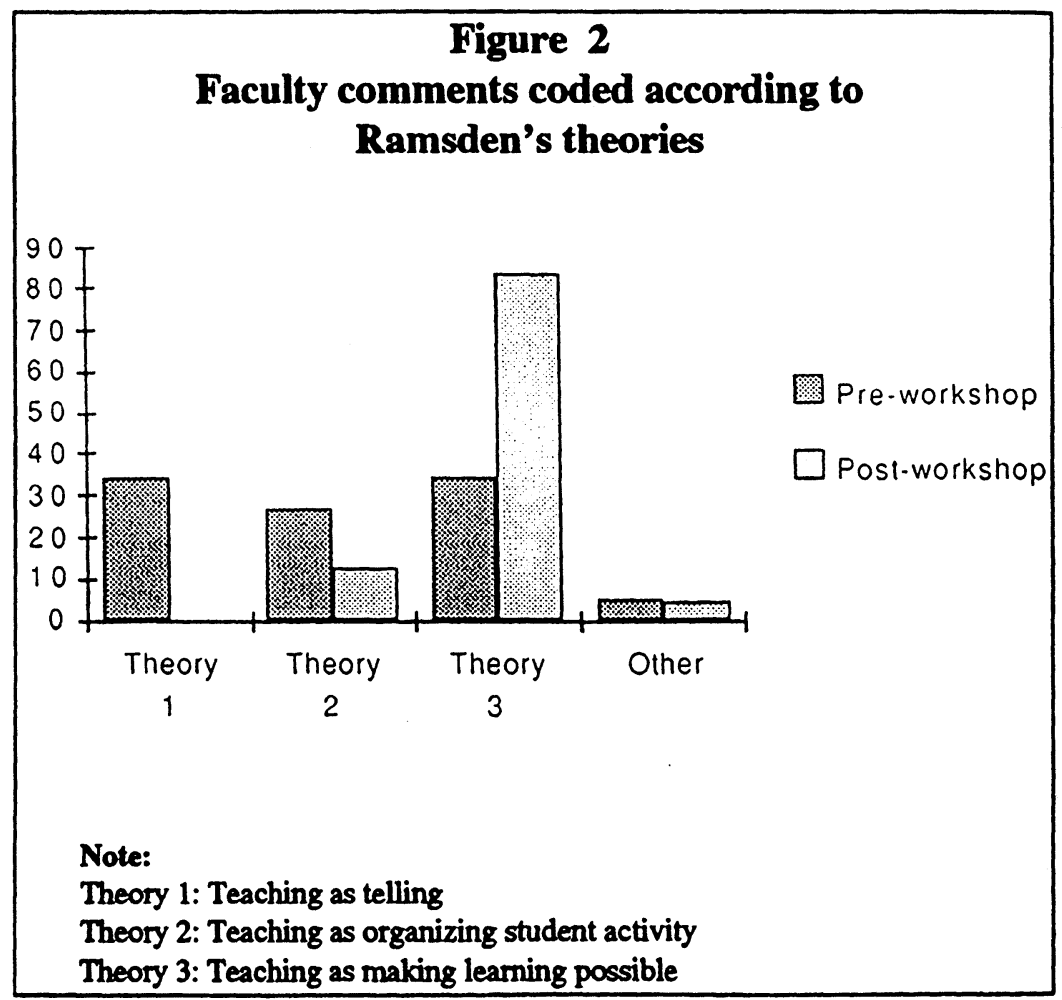




\section{Example of a comment from a student before the program}

Teaching is a tool through which to transmit knowledge to others, regardless of type of knowledge and to effectively present relevant information. It may or may not include the evaluation of learning. I'm not sure that the role of the teacher includes ensuring that the students are learning the material.

\section{Example of a comment from a faculty member before the program}

Teaching is to transmit to succeeding generations all knowledge and experience accumulated by preceding ones.

\section{Example of comments from a student after the program}

This course has really validated my views of the professor's role and how learning might be promoted in ways that depart from conventional norms...It [teaching] involves being a facilitator, an expert in a particular subject, a learner. The relationship between teaching, learning and assessment is an important one... The important aspect of teaching is ensuring or providing opportunities for students to articulate and explore their thinking.

\section{Example of comments from a faculty member after the program}

I do not remember exactly how I responded the last time this question was asked. I know that I now believe that a teacher should help students learn and understand... That it [teaching] must motivate and enable students to learn... The role of the professor is to structure activities so that appropriate learning takes place.

\section{Discussion}

The purpose of this paper was to describe a theory-based faculty development program and to provide some preliminary evidence as to its effectiveness in promoting change in thinking about teaching. We collected data from two different groups (graduate students and faculty) who had participated in two similar instructional formats (a credit course and workshop) on course design and teaching. Both formats were developed on the basis of Ramsden's (1992) theories of teaching 
in higher education and theories of adult education (Cranton, 1994; Mezirow, 1991). Statements on teaching, generated before and after one offering of the program, comprised the data.

Our findings indicate that in both formats of the instructional program, participants changed their focus from a view that teaching is primarily the transmission of knowledge to a more integrated view that sees teaching as the means of attaining specific learning outcomes. Our previous work suggests that once movement begins in this direction, it can have a snowballing effect on change at both the intellectual and the practical level (Amundsen, Gryspeerdt \& Moxness, 1993; Amundsen, Saroyan \& Frankman, in press). If we agree with previous assertions that a change in thinking is a necessary precursor to change in teaching practice (see for example Calderhead, 1991, Cranton, $1994 ; 1996)$, then the approach to faculty development we have described here is well justified.

While in general, after participating in the program, both faculty and students expressed a more sophisticated view of teaching according to Ramsden's (1992) framework, different trends were observed in the two groups. Students started out at a higher level, but faculty made the bigger leap and ended up further ahead than the students. Given that Ramsden's framework moves progressively toward a more student-centered approach, a possible explanation for this finding is that at the outset, being closer to the student/learner experience, graduate students wrote more statements from the learner's perspective. This placed them within the boundaries of Theory 2 . In contrast, faculty started with a view of teaching which may have been highly influenced by the norm of lecturing which tends to promote teaching as the transmission of knowledge and the role of the student as passive. Once engaged in the course design and micro-teaching sessions, faculty could have found the activities more meaningful because their position as instructors provided them with an immediate and real context to apply what they learned in the workshop. For the students, the use of the course they were designing might have been less immediate. Additionally, faculty actually worked on their course designs in small groups with constant input from both instructor and peers. Students, on the other hand, worked individually more of the time. Moreover, they had to submit the developed course as a final 
assignment and receive a grade for it. This may have diminished the impact of peer support as well as introduced a host of intervening variables, such as anxiety associated with the task. We may need to look at this difference in the two program formats because the anecdotal evidence from faculty supports the value of small group work, in particular, the greater amount of interaction with peers.

It is also possible that the intensive nature of the week-long workshop provided just the elements recommended by Kozma (1985) and resulted in a more powerful context for reflection and change. That is, faculty enjoyed a supportive collegial environment sanctioned by the university, with enough time to interact with colleagues, receive direction from Centre staff, and reflect upon the relevance of all of this for the design of their own course. In contrast, graduate students who took the course over a semester while attending to many other academic responsibilities simply did not have an equal opportunity to reflect with the same immediacy and intensity as the faculty members did.

The findings of this study have encouraged us to conduct a much larger study with greater rigor. We now have compiled data from four faculty workshops and more than 14 courses. More recently, we have expanded the questions that we ask our participants. As we collect more data, we plan to place greater emphasis on a more accurate description of the nature of the change process by increasing the frequency and types of measures used, and if possible, by matching the instructional formats. Most importantly, we hope to follow a subset of the participants into the classrooms to examine the time and the extent to which cognitive change impacts actual practice.

\section{Conclusion}

This paper responds to the repeated criticisms that faculty development activities are not well articulated within a theoretical context not in terms of what they ought to accomplish, and that the assessment of their impact is limited to the use of satisfaction ratings. Beyond this, the paper offers food for thought about the nature of faculty development activities. These modest findings are interesting enough to prompt us as faculty developers to question whether what we do 
provides instructors with interesting ideas as well as furthers their understanding of the broader teaching and learning process. We might question the impact of a short workshop on discussion techniques, for example, on an instructor who thinks of teaching as primarily the transmission of information. Perhaps we could enhance the effectiveness of that same workshop if we complemented it with a series of before and after discussion sessions during which participants could think about and articulate their philosophy of teaching. If we do succeed in effecting change in thinking about teaching, does this mean that there will be actual change in practice too? While we have not addressed this issue in the present paper, it is a natural follow-up question for us and one which we have already begun to explore. What we know so far is that the relationship between thinking and teaching practice is not straightforward; it varies from individual to individual and is greatly influenced by personal issues of confidence, the need for control, and the institutional context. We believe that we are developing a better understanding of the kind of effort it takes to improve teaching in higher education and the work it takes to develop a supportive institutional context.

\section{References}

Amundsen, C., Gryspeerdt, D., \& Moxness, K. (1993). Practice-centered inquiry: Developing more effective teaching in higher education. Review of Higher Education, 16, 329-353.

Amundsen, C., Saroyan, A., \& Frankman, M. (in press). Changing methods and metaphors: A case study of growth in university teaching. Journal of Excellence in College Teaching, 7.

Calderhead, J. (1991). The nature and growth of knowledge in student teaching. Teaching and Teacher Education, 7, 531-535.

Clark, C. (1991). Real lessons from imaginary teachers. Journal of Curriculum Studies, 23, 429-433.

Cranton, P. (1994). Self-directed and transformative instructional development. Journal of Higher Education, 65, 726-744.

Cranton, P. (1996). Professional development as transformative learning: New perspectives for teachers of adult. San Francisco: Jossey-Bass.

Dick, W., \& Carey, L. (1985). The systematic design of instruction (2nd ed.). Glenview, II: Scott. 
Elbaz, R. (1991). Research on teacher's knowledge: The evolution of a discourse. Journal of Curriculum Studies, 23, 1-19.

Grossman, P.L. (1991). Overcoming the apprenticeship of observation in teacher education coursework. Teaching and Teacher Education, 7, 345-357.

Kagan, D. M. (1991). How student teachers describe their pupils. Teaching and Teacher Education, 7, 455-466.

Kagan, D. M., \& Tippins, D. J. (1993). Classroom cases as gauges of professional growth. In M. O'Haire \& S. Odell (Bds.), Teacher education yearbook I: Diversity and teaching, (pp. 98-110). New York: Harcourt.

Kemp, J., Morrison, O., \& Ross, S. (1994). Designing effective instruction. New York: Macmillan.

Kozma, R. C. (1985). A grounded theory of instructional innovation in higher education. Journal of Higher Education, 56, 300-319.

Leinhardt, G., \& Greeno, J. G. (1986). The cognitive skill of teaching. Journal of Educational Psychology, 78, 75-95.

Levinson-Rose, J., \& Menges, R. (1981). Improving college teaching: A critical review of research. Review of Educational Research, 54, 403-434.

Little, J. (1982). Norms of collegiality and experimentation: Workplace conditions of school success. American Educational Research Journah 19, 325-340.

Mezirow, J. (1991). Transformative dimensions of adult learning. San Francisco: JosseyBass.

Pajares, M. (1992). Teachers' beliefs and educational research: Cleaning up a messy construct. Review of Educational Research, 62, 307-332.

Pugach, M., \& Johnson, C. (1990). Fostering the continued democratization of consultation through action research. Teacher Education and Special Education, 13, 240-245.

Ramsden, P. (1983). Institutional variations in British students' approaches to learning and experiences of teaching. Journal of Higher Education, 12, 691-705.

Ramsden, P. (1988a). Context and strategy: Situational differences in learning. In $\mathbf{R}$. Schmeck (Ed.), Learning strategies and learning styles (pp. 159-184). New York: Plenum.

Ramsden, P. (1988b). Improving learning: New perspectives. London: Kogan Page.

Ramsden, P. (1992). Learning to teach in higher education. London: Routledge.

Ramsden, P., \& Entwistle, N. (1981). Effects of academic departments on students' approaches to studying. British Journal of Educational Psychology, 51, 368-383.

Schön, D. A. (1983). The reflective practitioner. New York: Basic Books.

Sherman, T., Barksdale, M., \& Reif, G. (1987). The quest for excellence in university teaching. Journal of Higher Education, 48, 66-83.

Shulman, L. (1987). Knowledge and teaching: Foundations of the new reform. Harvard Educational Review, 57, 1-22.

Van Note Chism, N., \& Sanders, D. (1986). The place of practice-centered inquiry in a faculty development program. In M. Svinicki, J.G. Kurfiss, \& J. Stone (Eds.), To 
Improve the Academy, Vol. 5 (pp.56-64). Stillwater: OK: New Forums Press and the Professional and Organizational Development Network in Higher Education.

Weimer, M., \& Lenze, L. F. (1991). Instructional interventions: A review of the literature on efforts to improve instruction. In J. C. Smart (Ed.), Higher education: Handbook of theory and research, Vol. 7 (pp. 294-333). New York: Agathon Press.

Contact:

Alenoush Saroyan

Centre for University Teaching and Learning

McGill University

3700 McTavish Street

Montréal, Québéc

Canada

H3A 1 Y2

(514) 398-6648 Phone

(514) 398-4679 FAX

Saroyan@Education.McGill.CA

Alenoush Saroyan is an Associate Professor in the Department of Educational and Counseling Psychology and the Centre for University Teaching and Learning at McGill University. Her research is on the development and assessment of pedagogical competencies of postsecondary educators. She teaches graduate courses in instructional psychology and serves on a number of committees on university teaching and learning.

Cheryl Amundsen is an Associate Professor in the Department of Educational and Counseling Psychology and the Centre for University Teaching and Learning of McGill University. Her research is situated in the contexts of traditional higher education and distance education where the focus is the development of pedagogical knowledge and instructional decision-making.

Cao $\mathrm{Li}$ is a doctoral student in the Department of Educational and Counseling Psychology at McGill University. He received his M.Ed. from Queen's University, with specialization in Curriculum and Instruction. He is currently involved in research on teacher thinking and faculty development.

This paper was initially presented at the Annual Meeting of the American Educational Research Association in April 1994 in New Orleans, LA.

The preparation of this paper was supported in part by a grant from the Social Sciences and Humanities Research Council of Canada.

The authors wish to thank Sue Davies for her assistance in compiling and coding the data. 


\section{Appendix A}

Teaching and Learning: Instruction in Higher Education

Needs Assessment

Name:

Phone:

Your Department:

Degree sought:

Please define teaching as you view it at the present time using the following questions to prompt your thoughts, if you choose. (Use the back of this sheet if necessary.)

What is the role of the teacher/professor?

What kinds of teaching activities might a teacher /professor engage in?

What are the most important aspects of teaching?

What experience would you say has most influenced the way you think about teaching?

Other thoughts?

2. Which course(s) (if any) are you currently appointed to as a TA or part time instructor?

3. What is your responsibility in this course(s)?

4. Do you know yet if you will be assigned to a course in September 1994. If so, which course?

5. What previous teaching experience have you had?

6. Have your ever developed (or helped develop) a new course? 
7. Describe various instructional methods that you may have used (e.g., lecture, lab, group tutorial, one-to-one tutorial).

8. Have there been any student demands which you have found difficult to meet?

9. Have you ever developed (from scratch) tests (written, oral, or performance)? . If yes, in what content area(s)? Please also describe your experience (e.g., what you found difficult or rewarding, what worked or didn't work).

10. Describe any anxieties you may have related to teaching (e.g., speaking in front of a group, grading, relationship with the professor with whom you are working, etc.).

11. Describe any positive experiences you may have had with teaching (e.g., things you know or have been told you do well, student feedback, etc.).

12. What kind of career do you foresee for yourself at this point in your life?

13. What do you expect (or hope) to learn from this course? 


\section{Appendix B}

Course Design and Teaching Workshop

May 17-24, 1993

Name:

\section{Needs Assessment}

1. How many years/months of university teaching experience do you have?

2. What courses have you taught? Please indicate course name, level, and class size

3. Have your ever developed (or helped develop) a new course? Please describe your experience(s).

4. If you have developed a new course, what resources did you draw on (e.g., personal experience, books, colleagues, workshops, etc.)?

5. How would you describe your typical teaching method (e.g., lecturing, group tutorial, one-to-one tutorial, technology driven, clinical teaching, discussion, etc.)?

6. In addition to your standard method, what other teaching methods have you used?

7. Have there been any student demands which you have found difficult to meet?

8. Describe any anxieties you may have related to teaching (e.g., speaking in front of a group, grading, relationship with colleagues/chair, etc.). 
9. Describe any positive experiences you may have had with teaching (e.g., things you know or have been told you do well, student feedback, etc.).

10. During the time you have been teaching in higher education, have you made changes in the way you teach or in your teaching materials? If so, please describe.

11. During the time you have been teaching in higher education, would you say that your view of (or way of thinking about) teaching has changed in any way? If so, please describe.

12. What do you expect to get out of this workshop?

13. Please define teaching as you view it at the present time. Some ideas to prompt your thoughts might be: What is the role of the teacher/professor? What kinds of teaching activities might a teacher/professor engage in? What are the most important aspects of teaching? (Please use the back of this sheet if you need more space.)

14. Three views of teaching are presented below. Please indicate the extent to which you agree with each view.

Teaching is the transmission of knowledge.

$\begin{array}{llllllll}\text { Strongly disagree } & 1 & 2 & 3 & 4 & 5 & \text { Strongly agree }\end{array}$

Teaching is concerned with the content of what students have to learn in relation to how it should be taught.

$\begin{array}{lllllll}\text { Strongly disagree } & 1 & 2 & 3 & 4 & 5 & \text { Strongly agree }\end{array}$ 
Teaching is the organization of student activity. $\begin{array}{lllllll}\text { Strongly disagree } & 1 & 2 & 3 & 4 & 5 & \text { Strongly agree }\end{array}$ 